\title{
Influencia de la filosofía europea en la filosofía chilena y latinoamericana. La recepción del pensamiento heideggeriano $y$ las experiencias de traducción ${ }^{1}$
}

\author{
Dina V. Picotti C. \\ UNCS, Argentina
}

Como ya expresara en otra oportunidad ${ }^{2}$, por lo menos desde la aparición de Ser y tiempo el pensamiento de M. Heidegger tuvo gran resonancia en los medios filosóficos, y aun en general culturales, no sólo alemanes y europeos sino mundiales. La confrontación con la metafísica y sus grandes planteos desde la dimensión originaria de la olvidada pregunta por el ser mismo y desde allí la posibilidad de un planteo también más originario de las grandes cuestiones que siempre la animaron como la verdad, el hombre, el pensar y la acción, pasando por el lenguaje, movilizaron no sólo a la filosofía sino a las expectativas de diálogo con otros modos históricos de pensar, de allí la no casual gran resonancia en ámbitos no europeos, como el asiático del este y latinoamericano. A su vez, la posibilidad de tratar desde tal dimensión originaria del ser como acaecer la historia y las grandes cuestiones de nuestro tiempo, como la pregunta por la técnica, el desafío del fin de la metafísica hacia otro comienzo del pensar, para entre otras cosas poder, más allá de las pretensiones y juegos de dominio, habitar un mundo, lo convirtieron en el pensamiento actual más significativo junto con el de Nietzsche. Resulta de este modo innegable la gran influencia de Heidegger en el pensamiento contemporáneo, no sólo filosófico, sino teológico, histórico, lingüístico, estético, etc.

1 Conferencia pronunciada en la Fundación Millas de Santiago de Chile el 15 de abril de 2015.

2 Heidegger - una introducción, Buenos Aires, Edit. Quadrata/Biblioteca Nacional, 2010. 
También ha sido fuertemente criticado y malentendido, a pesar de su permanente preocupación por explicitar el sentido de sus planteos y de su lenguaje con respecto a la tradición filosófica o a la comprensión vigente y habitual, y de reclamar la actitud meditante del pensador y la exigencia de andar los propios caminos.

Sobre todo ha sido criticado y en buena parte malentendido su compromiso político y el silencio guardado frente al nazismo a partir de su retirada en pleno auge del sistema, si bien voces primeramente muy críticas supieron luego dar testimonios más favorables fundados en la totalidad de la vida y obra de este pensador.

Sin embargo, ello no ha impedido ni aminorado su gran influencia y capacidad de continuar suscitando profundo interés, precisamente ante el desafío actual del pensar, con respecto a lo cual ha merecido el nombre de 'maestro de Alemania's'.

En todo caso es imposible permanecer indiferentes, al menos por dos grandes razones: 1 . Por su magistral diálogo con la tradición filosófica, en el que resalta los grandes planteos como 'cumbres' en sus modos, logros y límites, para retomar la tarea pensante como verdadera síntesis histórica, en la que el pasado reúne un espacio de experiencia para ser actualizado y abierto a nuevas proyecciones. 2. Por la posibilidad que el otro comienzo abre, desde el ser como acaecer, de un planteo más originario de las grandes cuestiones que preocupan a nuestros tiempos y la factibilidad de diálogo con otras acuñaciones de ser y modos pensantes y sus respectivos recursos, con toda la historia humana.

En América Latina su recepción e influencia ha sido importante, proporcionalmente mayor que en los países europeos, y en los tres niveles ${ }^{4}$ de: 1) la lectura como intento de comprensión de la propuesta del autor, involucrando la traducción, que supone el ejercicio pensante de traspaso de los conceptos filosóficos, y la interpretación; 2) la

3 Véase la obra así titulada de Rüdiger Safranski, Ein Meister aus Deutschland. Martin Heidegger und seine Zeit, Carl Hanser Verlag, München-Wien, 1994.

4 Como plantea Andrea Cortés, Heidegger-en-Latinoamérica", tesis doctoral, Universidad Libre de Berlin, 2006. 
explicación y exposición comentada de la obra, 3) el más creativo de un pensar que se configura a partir de los caminos abiertos por el pensador.

Se inició, como podría esperarse, entre el grupo de filósofos que, por su formación en Alemania, podían leer durante los años treinta del siglo XX los textos en su lengua original ${ }^{5}$. Comparados con sus colegas españoles, los filósofos latinoamericanos mostraron un mayor entusiasmo y una auténtica devoción en la recepción de Sein und Zeit, por lo que a fines de la década de los años cincuenta de ese siglo los escritos heideggerianos habían alcanzado una significativa influencia. La rapidez de la recepción hispanoamericana pudo haber sido propiciada por el "movimiento fenomenológico" que ya existía a comienzos de la década de los años treinta, constituido por la tradición de lectura de los escritos de Max Scheler, Edmund Husserl y Nicolai Hartmann, de tal manera que se reconoce en esta "escuela alemana" el mayor poder de impacto en el pensamiento filosófico hispanoamericano, después de siglos de influencia casi exclusiva de la escolástica. En ello tuvo su parte el ascendiente que sobre ellos ejerció José Ortega y Gasset y la labor divulgadora de su Revista de Occidente que comenzó a publicarse desde 1922. Esta influencia se tornó más próxima en la década siguiente a causa del exilio de un buen número de filósofos españoles en medio de la guerra civil de su patria, España: hombres como José Gaos, José Ferrater Mora, Juan David García Bacca y Manuel García Morente fueron dinámicos agentes en la tarea de introducción de la filosofía alemana en México, Venezuela y Argentina, no sólo por el conocimiento que traían de la lengua alemana, sino por su actividad magisterial. A las traducciones de los 'transterrados' españoles se sumaron las de los jóvenes hispanoamericanos que pudieron asistir a los cursos de Heidegger en Alemania, tales como los peruanos Alberto Wagner de Reyna y Víctor Li Carrillo, los argentinos Carlos Astrada y Osvaldo Pugliese, el ítalo mexicano Alejandro Rossi y el colombiano

5 Consideramos la detallada exposición de A. Martínez Garnica, "Crónica de la recepción de Heidegger en Hispanoamérica", Revista Santander, 2006, que toma nota de la sucesión de producciones principales. 
Rafael Gutiérrez Girardot. La primera edición castellana de Sein und Zeit, aparecida en 1951 en México, abrió definitivamente la puerta al lector no especializado que se interesaba por la recepción de las ideas fundamentales de Heidegger. En ésta, no obstante, pueden reconocerse varias lecturas. La primera de ellas, pese a la pregunta metafísica expresamente manifestada por Heidegger, fue una lectura existencialista: tal es el sentido de la temprana recepción argentina de Carlos Astrada, José Salas Subirat, Lorenzo Carnell, de algunos mexicanos como Leopoldo Zea y Luis Villoro y del cubano Humberto Piñera Llera. Una segunda lectura "ecléctica" combinó la aceptación de algunas ideas con el rechazo de otras, bien para reelaborar un pensamiento católico, como en el caso de A. Wagner de Reyna, Oswaldo Robles, Ismael Quiles S.J., Cayetano Betancur, o para iniciar una filosofía del 'ser latinoamericano' en Samuel Ramos y José Romano Muñoz. Hay que reconocer también una oposición al pensamiento heideggeriano, fundada en la conducta política del filósofo durante la década de los años treinta como en Alejandro Korn, Antonio Caso, José Vasconcelos y recientemente Víctor Farías, o en argumentos filosóficos provenientes del neokantismo y otras fuentes, como en Francisco Romero, Francisco Larroyo, Andrés Avelino García Solano, Antonio Gómez Robledo. Después de la divulgación de la Carta sobre el humanismo se debilitó la lectura existencialista, predominando desde entonces la lectura ontológica sugerida por Heidegger en sus cursos, la cual coexiste hasta hoy en compañía de la postura adversa a su recepción, que no es más que una resistencia a su lectura motivada en razones políticas, no sólo de los "antifascistas", sino también los "marxistas" que calificaban sus obras de "idealismo burgués".

El magisterio de los transterrados: La noticia de la aparición de Sein und Zeit, durante la primavera de 1927, pudo conocerse casi inmediatamente en España gracias al seguimiento que algunos de sus filósofos más connotados estaban haciendo de las novedades de la filosofía alemana. Don José Gaos recordaba que en 1930, cuando llegó de visita a Madrid, había encontrado a José Ortega y Gasset conversando con el poeta Jorge Guillén, en la tertulia de la Revista de Occidente, sobre el significado de esta obra de Heidegger. En esa conversación, Ortega y Gasset había sostenido que en el pensamiento 
del filósofo de la Universidad de Friburgo "la filosofía visita a domicilio", es decir, que bajaba del cielo a la tierra para entrar por las casas de los hombres. El entusiasmo por la "novedad alemana" hizo que Gaos adquiriera de inmediato su ejemplar de Sein und Zeit, si bien sólo tres años más tarde comenzaría a leerlo con detenimiento. En la Revista de Occidente, que dirigía el propio Ortega y Gasset, no quedó registro alguno de la lectura española del texto heideggeriano, quizás porque el grupo de quienes podían leerlo en su idioma original a comienzos de los años treinta era muy reducido: el propio Ortega y Gasset, su discípulo Xavier Zubiri, Eugenio Imaz, José Gaos, Juan David García Bacca y pocos más. De todos modos, Zubiri e Imaz procedieron a traducir el texto heideggeriano ¿Qué es la metafísica?, para su publicación en la sexta entrega de la revista madrileña Cruz y raya (1931). Xavier Zubiri pudo asistir durante los años 1931 y 1932 a los cursos impartidos en la Universidad de Friburgo por Heidegger, llegando incluso a compartir con el filósofo sus paseos por el campo y las jornadas de alpinismo. Al regresar a Madrid contagió con su entusiasmo a José Gaos, quien para 1933 ya había empezado a traducir Sein und Zeit, recibiendo semanalmente en su casa la visita magisterial de Zubiri. Curiosamente, en las obras de Zubiri no ha quedado una clara referencia de ese entusiasmo por Heidegger ni un desarrollo de las direcciones ontológicas trazadas por aquél. Pese a que no produjeron estudios particulares de los temas sugeridos por Sein und Zeit, estos filósofos españoles siguieron con atención las primeras exposiciones críticas del pensamiento heideggeriano aparecidas durante la década siguiente a su publicación. Así por ejemplo, José Gaos leyó los trabajos de Fritz Heinemann, Augusto Messer, Georges Gurvitch, Alphonse de Waehlens y Alberto Wagner de Reyna durante esa época. La circunstancia de la Guerra Civil española detuvo la normalidad de la vida académica y produjo el exilio de un buen número de profesores universitarios hacia Hispanoamérica. Con ellos se fortalecieron los espacios universitarios que la filosofía ya tenía en algunos países (México, Argentina, Venezuela), pues gracias al conocimiento de la lengua alemana que aportaron contribuyeron decisivamente a la traducción de las obras de los pensadores alemanes. Baste citar sólo algunos nombres de estos exilados españoles que pusieron al alcance 
del público hispanoamericano las obras de Heidegger (José Gaos y Juan David García Bacca), de Dilthey (Eugenio Imaz), de Marx, Hegel y Cassirer (Wenceslao Roces).

México: El proyecto de constitución de La Casa de España en la ciudad de México, un espacio académico ofrecido por el gobierno mexicano a los intelectuales españoles del exilio interesados en proseguir los trabajos que ya habían iniciado en la península, permitió el agrupamiento de quienes dejarían una honda huella en la filosofía e historiografía mexicana del decenio de los años cuarenta: José Gaos, Joaquín Xirau, Juan David García Bacca, Juan Roura, María Zambrano, Joaquín Alvarez Pastor, Eduardo Nicol, Eugenio Imaz, Luis de Recasens, Ramón Iglesia y Rafael Altamira. La editorial Fondo de Cultura Económica y El Colegio de México -sucesor de los trabajos de la Casa de Españafueron sus espacios de trabajo privilegiados, una vez que algunos de ellos abandonaron la idea del regreso a su patria y se convirtieron en auténticos 'transterrados', según la afortunada expresión de José Gaos. La cátedra de Filosofía instituida por este último en la Universidad Nacional Autónoma de México fue el escenario privilegiado para la recepción del pensamiento heideggeriano en este país, pues fue allí donde se forjó la primera versión castellana de dicha obra. Este esfuerzo de traducción de Sein und Zeit rindió sus frutos en 1951, año en que salió al público gracias al Fondo de Cultura Económica. Este hito es significativo, pues la versión italiana apenas saldría dos años después de la de Gaos. Desde entonces han aparecido de la versión del FCE por lo menos ocho reediciones en México y tres reimpresiones en Argentina, a la que se agrega una en España. Eugenio Imaz pudo registrar en1948, antes de la aparición de El ser y el tiempo, la intensidad de la recepción mexicana del pensamiento de Heidegger como "el espectáculo de la boga angustiosa que el heideggerianismo está conociendo entre nosotros". Una prueba de la atención que se prestaba a todos los movimientos del filósofo alemán es el artículo "Heidegger y el humanismo", escrito en ese año por el mismo Imaz para divulgar la noticia de la aparición, durante el año anterior, de la Carta sobre el humanismo que Heidegger había escrito para deslindar sus posiciones con respecto al existencialismo sartreano. Este artículo de Imaz tiene un gran valor porque es una señal del avance alcanzado 
en la recepción del pensamiento heideggeriano. Dos ideas expuestas por él así lo indican: la primera es su identificación del grave problema que significa la incorporación de los neologismos alemanes aparecidos en Sein und Zeit al pensamiento en idioma castellano: ...lo primero que tenemos que hacer es pensar, si podemos y en la medida en que lo podamos, en español lo que Heidegger pensó en alemán. Porque la primera y más fatal traición a su pensamiento consistiría en germanizar el español cuando él está empeñado en germanizar hasta la raíz la expresión de su pensamiento para ser más fiel a él. La segunda idea es la identificación de las fuentes del pensamiento heideggeriano, es decir, en vez de que Imaz repitiese las supuestas fuentes existencialistas de Sein und Zeit, subvertidas profundamente por la Carta sobre el humanismo, propuso en cambio una asociación del pensamiento de Heidegger con la poesía de Hölderlin: "La tragedia de Empédocles de Hölderlin me parece como el argumento principal del pensamiento de Heidegger". Esta posición la derivó Imaz de su familiaridad con las dificultades de la traducción de la filosofía alemana, dado que él mismo se encontraba a la sazón trabajando en las obras de Dilthey, lo cual le llevó a proponer el ingreso a los textos de los filósofos alemanes dando un rodeo por la propia literatura alemana. El trabajo de traducción realizado por Gaos fue complementado en México por G. Ibscher Roth y el filósofo Samuel Ramos. Los estudios realizados en México sobre diversos aspectos de la filosofía de Heidegger son abundantes. Comenzando por la propia introducción a Ser y tiempo de Gaos, que a partir de la segunda edición fue separada del texto para su publicación autónoma por el mismo Fondo de Cultura Económica, y de sus artículos difundidos en diversas revistas. Encontramos luego a Samuel Ramos presentando, bajo el título de La estética de Martín Heidegger, la edición hecha por la misma editorial de los textos heideggerianos conocidos como Origen de la obra de arte y Hölderlin y la esencia de la poesía. Adolfo Menéndez Samara publicó tempranamente dos breves ensayos sobre el filósofo, referidos a su percepción de la esencia de la poesía y al concepto de la Nada, en comparación con el de Bergson. Jesús Rodolfo Santander intentó un estudio de Sein und Zeit a la luz de la filosofía marxista del trabajo. La revista Diánoia ha recogido pocos estudios heideggerianos, pero llaman la atención el ya citado 
de José Gaos y uno de Fernando Salmerón. Más recientemente, dos investigadores de la Escuela de Filosofía de la UNAM han publicado traducciones de la versión francesa de dos textos poco conocidos de Heidegger: el Epílogo agregado en 1943 a la conferencia de 1929 titulada ¿Qué es metafísica?, y el artículo conocido como Questions IV (El arte y el espacio). La lectura existencialista de Heidegger en México tuvo sus mejores exponentes en Luis Villoro y Leopoldo Zea, quien derivó hacia los estudios de "lo latinoamericano". Las lecturas eclécticas estuvieron representadas por Samuel Ramos, José Romano Muñoz, Ismael Quiles, S.J. y el neotomista Oswaldo Robles. La oposición mexicana a Heidegger también tuvo sus mejores exponentes en Antonio Caso, Francisco Larroyo, Antonio Gómez Robledo y Adolfo Sánchez Vázquez.

Argentina: La recepción del pensamiento de Heidegger en Argentina fue contemporánea de la recepción española y previa al proceso mexicano, pues durante la década de los años treinta ya dos filósofos, Carlos Astrada y Carlos Erro, habían comenzado a publicar estudios sobre la problemática de Sein und Zeit. La divulgación había comenzado muy pronto, pues en 1933 ya la revista Verbum, órgano del Centro de Estudiantes de Filosofía y Letras de Buenos Aires, había publicado en su entrega 83 diversos textos relativos al filósofo alemán, entre los que destacamos la reseña de Sein und Zeit escrita por Gilbert Ryle. El caso de Carlos Astrada es especial, pues habiendo sido alumno de Heidegger antes de la Segunda Guerra Mundial, pudo escribir en 1936 el primer estudio crítico general del pensamiento heideggeriano en lengua castellana, al cual seguirían trabajos posteriores. Su lectura de la obra de su maestro fue decididamente existencialista, encabezando por ello al grupo de los filósofos argentinos que se inscribieron en tal dirección de lectura. Por su parte, Carlos Erro publicó en 1938 su propia exposición analítica de la filosofía heideggeriana. Los filósofos argentinos han hecho desde entonces un significativo aporte a las traducciones castellanas de los escritos del filósofo alemán. Esa larga lista de traductores fue inaugurada por Raimundo Lida y seguida por el ya mencionado Carlos Astrada. Inscribimos en ella también a Emilio Estiú, A. Goller de Walter, Haraldo Kahnemann, Hernán Zucchi, Adolfo P. Carpio, Ernesto Garzón 
Valdés, Ruth Fischer de Walker, Oberdan Caletti, Norberto V. Silvetti, la pareja formada por Bruno y Alicia C. Piccione, y las formadas por Karin von Wrangel y Arturo García Astrada, así como por Eduardo García Belsunce y Zoltan Szankay. La apoteosis de la recepción argentina del pensamiento de Heidegger estuvo a punto de ocurrir en el año 1949, si el filósofo hubiera podido aceptar la invitación a asistir al Primer Congreso Nacional de Filosofía que se realizó en Mendoza. Este evento revela que en aquella época Argentina era el centro latinoamericano de la recepción de la filosofía alemana y, en general, europea, pues la congregación en la Universidad Nacional de Cuyo -entre el 30 de marzo y el 9 de abril de dicho año- de un nutrido grupo de filósofos europeos (N. Abbagnano, B. Croce, G. della Volpe, Eugen Fink, H.G. Gadamer, N. Hartmann, J. Hippolite, W. Jaeger, Karl Jaspers, Gabriel Marcel, J. Maritain, Bertrand Russell, E. Spranger, Julián Marías y otros) con filósofos de todos los países latinoamericanos fue un evento que difícilmente podrá repetirse en Hispanoamérica. El mensaje enviado por Heidegger al presidente de este Congreso dio cuenta de su doble negativa a viajar para realizar el proyecto de ofrecer una gira de conferencias por las universidades argentinas y una conferencia en el evento. El número de filósofos existentes en la Argentina de los años cuarenta del siglo XX era el más grande de cuantos existían en Hispanoamérica, algo que puede explicar también el papel jugado por el nutrido grupo de las editoriales argentinas (Nova, Sudamérica, Sur, Thor, Devenir, Siglo Veinte) en la recepción del pensamiento europeo durante las décadas de los años cincuenta y sesenta del siglo XX. Además del grupo bonaerense interesado en el pensamiento heideggeriano, podemos identificar al comenzar la década de los años sesenta otros tres grupos de filósofos dedicados al estudio de los problemas de la Metafísica y del pensamiento de Heidegger. El primero de ellos se concentraba en el Instituto de Filosofía de la Universidad Nacional del Litoral, en Rosario, que dirigieron Adolfo P. Carpio y Angel J. Cappelletti. Allí se produjeron varios trabajos sobre Heidegger, empezando por los de Adolfo P. Carpio, y siguiendo con los de Francisco Aguilar, Raúl Echauri, Rosa María Ravera y Rubén Vasconi. El segundo grupo se concentró en la Facultad de Filosofía y Humanidades de la Universi- 
dad Nacional de Tucumán, dirigida por Arturo García Estrada, uno de los traductores de "Hebel, el amigo de la casa". En las Jornadas de Metafísica que éste organizó en Tucumán entre el 21 y 29 de mayo de 1961, un evento que reunió a la casi totalidad de filósofos argentinos involucrados con la enseñanza de la Metafísica, se presentaron tres ponencias sobre el pensamiento heideggeriano: la del propio García Estrada, la de Angel Jorge Casares y una de Miguel A. Virasoro. En opinión de Francisco Aguilar, quien hizo una crónica del evento, las de los dos últimos habrían estado "muy alejadas, y a veces tergiversantes, del rico pensar que Heidegger ha descubierto para nuestra contemporaneidad". El tercer grupo se expresaba en la revista Philosophia del Instituto de Filosofía de Mendoza, en la cual publicaron estudios de tema heideggeriano los profesores Oward $\mathrm{H}$. Ferrari, A. Orlando Pugliese y Carlos L. Ceriotto. La oposición argentina a la recepción heideggeriana estuvo representada por Alejandro Korn, quien después de la renuncia del filósofo a la rectoría de su universidad escribió "Una posición argentina contra la supuesta afiliación de Heidegger al nacionalsocialismo". En Argentina se produjo además un caso fallido de una traducción de un texto heideggeriano: la versión hecha por José Rovira Armengol de Holzwege (Sendas perdidas, Losada, Buenos Aires, 1960) resultó tan plagada de errores que después de recibir muchas críticas se dio por inutilizable. Trabajos más recientes son los de Mario C. Casalla, quien se esforzó por situar la lectura de Heidegger en la Argentina, recogiendo de paso una abundante bibliografía castellana sobre el pensamiento del filósofo para el período 1936-1970. Ese esfuerzo de recolección bibliográfica castellana ya había tenido un buen antecedente argentino en Víctor R. Martín. Otros estudios fueron realizados por Beda Alleman, Octavio N. Derisi y el inmigrante italiano Enzo Paci. Así como los filósofos españoles del exilio de la guerra civil fueron determinantes en la recepción mexicana del pensamiento heideggeriano, podemos decir lo mismo con respecto a los filósofos argentinos que emigraron a Puerto Rico. La influencia de Angel Jorge Casares fue definitiva en el Departamento de Filosofía de la Universidad de Puerto Rico para la recepción portorriqueña, no sólo por sus traducciones y estudios, sino porque abrió la revista Diálogos a otro filósofo argentino, 
Mario A. Presas, responsable de investigaciones recientes sobre la biografía y el pensamiento de Heidegger. Se agregan a ellos, en el mismo Departamento de la Universidad de Puerto Rico, Miguel A. Badía Cabrera y Carla Cordua. En la actualidad el pensamiento de M.Heidegger sigue ocupando un lugar importante en las cátedras universitarias y en la producción filosófica, aunque en el contexto posmoderno de numerosos autores y posiciones y de una interpretación ecléctica de su obra; se han agotado las ediciones de mis propias traducciones de las obras que explicitan 'el otro comienzo del pensar' como Aportes a la filosofía-acerca del evento, Meditación, Sobre el comienzo, Historia del ser, así como el tomo que comprende dos trabajos dedicados a Hegel y el tomo titulado Acerca de Ernst Jünger ${ }^{6}$ referido a lo que llama el acabamiento de la metafísica y la cuestión del poder. La misma editorial publicó Conmemorando a M. Heidegger-Dossier Imago Agenda 1997-2000, una serie de trabajos referidos a diferentes aspectos del pensamiento del filósofo.

Uruguay: se destacó Juan Llambías de Azevedo, no sólo por su hipótesis acerca de los dos Heideggeres sino por la entrevista que hizo el 13 de mayo de 1955 al filósofo en su casa de Friburgo. Por lo demás, Aníbal del Campo publicó en la revista Número de Montevideo (15-17, 1951) el artículo titulado "El retorno al fundamento de la metafísica", o sea el prólogo a "¿Qué es Metafísica?", mientras que J. Sasso ensayó una interpretación de "La teoría de la culpabilidad en Heidegger" en los Cuadernos uruguayos de Filosofía (No. 5, 1968).

Chile: La recepción del pensamiento heideggeriano en Chile se debió, en buena medida, a la labor magisterial de un discípulo de Heidegger y de Julián Marías, el profesor español Francisco Soler Grimma (19241982), quien después de haber estado un tiempo en la Universidad Nacional de Colombia se radicó en Santiago, donde divulgó sus traducciones en las cuatro universidades donde trabajó. Sus propios trabajos son todos de tema heideggeriano: El origen de la obra de arte

6 Publicados por Biblioteca Internacional M.Heidegger/Biblos/El hilo de Ariadna, Buenos Aires. 
y la verdad en Heidegger, y sus póstumos Apuntes acerca del pensar de Heidegger (Andrés Bello, Santiago, 1983). Luis Hernández, Juan de Dios Vial, E. Grassi y Jorge Acevedo completan el esfuerzo de la recepción chilena del pensamiento del filósofo alemán, con la especial posición de Víctor Farías, un filósofo de la Universidad Católica de Santiago que emigró a Alemania, donde actúa como profesor de la Universidad Libre de Berlín. Se ha hecho célebre por haber promovido en muchas lenguas una dura crítica al filósofo, basándose en sus investigaciones sobre la adhesión de Heidegger al nacionalsocialismo alemán. Pese a tal crítica, debemos a Farías la versión castellana de las Lecciones sobre Lógica dadas por Heidegger durante el semestre de verano de 1934, según el texto conservado en el legado de una de sus alumnas, Helene Weiss. Un hito importante de la recepción chilena es la segunda versión castellana de Sein und Zeit que realizó el profesor Jorge E. Rivera, publicada originalmente en 1997 por la Editorial Universitaria (Santiago de Chile) y recientemente por Trotta, un paso adelante con respecto a la versión inicial de Gaos. Ha seguido la traducción de Los himnos de Hölderlin "Germania" y "El Rin" de Ana C. Merino Riofrío, publicada en 2010 por la Editorial Biblioteca Internacional M. Heidegger/Biblos, Buenos Aires.

Venezuela: La actividad magisterial de Juan David García Bacca, otro de los filósofos españoles del exilio, fue el eje de la recepción de las ideas de Heidegger en Venezuela. Después de una breve temporada en Quito (1939-1942) y de una permanencia en México (1942-1947), García Bacca se radicó definitivamente en Caracas, donde realizó una fecunda labor de divulgación de la filosofía desde la Universidad Central de Venezuela. Además de sus traducciones de textos heideggerianos, García Bacca se esforzó por divulgar aspectos del pensamiento del filósofo alemán en conferencias públicas y en su cátedra universitaria de la Facultad de Filosofía, pero también en artículos publicados en diversas revistas. En la obra de Ernesto Mayz Vallenilla podemos seguir una cierta tradición de la Universidad Central en la recepción del pensamiento heideggeriano. Su Ontología del conocimiento (U. Central de Venezuela, Caracas, 1960) se agrega a la divulgación en Venezuela de las traducciones del argentino E. García Belsunce y del colombiano Gutiérrez Girardot. Posteriormente Mayz 
Vallenilla publicó Del hombre y su alienación (Colección Pensamiento y Verdad, Caracas, 1966) y los Fundamentos de la meta-técnica (Monte Ávila, Caracas, 1990), mientras que Eduardo Vásquez experimentó una comparación del pensamiento heideggeriano con el de Marx con respecto al concepto de alienación. Juan Antonio Nuño. Por otra parte, Alberto Rosales, un profesor de la Universidad Simón Bolívar de Caracas y doctor en filosofía por la Universidad de Colonia, no sólo ha estudiado en profundidad el pensamiento heideggeriano sino que también ha contribuido a su divulgación traduciendo el estudio Schelling y la libertad humana, publicado en Caracas por Monte Ávila (1990). En el programa de postgrado en Filosofía de la Universidad de los Andes (Mérida) se realizaron algunos esfuerzos de recepción: el profesor Agustín Rodríguez publicó en el número 6 (abril de 1994) de la revista Filosofía de dicho programa un artículo titulado "Meta y camino de Ser y Tiempo", y en el número 9-10 (1996-1997) se publicó la traducción que hizo Pompeyo Ramos del Discurso del filósofo al tomar posesión de la rectoría de la Universidad de Friburgo de Brisgovia.

Perú: Alberto Wagner de Reyna fue, sin duda, el principal responsable de la recepción peruana de Heidegger. Después de cursar sus estudios secundarios en Lima y Berna, hizo sus cursos profesionales en la Universidad Central del Perú. En Friburgo pudo asistir a los cursos de Heidegger y de Martin Honecker. Desde su cátedra de Lógica en la Universidad Católica del Perú, Wagner de Reyna produjo varias traducciones de textos del filósofo alemán y el estudio La ontología fundamental de Heidegger. Su motivo y significación (Losada, Buenos Aires, 1939), con nota preliminar de Francisco Romero. Al Congreso Argentino de Filosofía (1949) llevó como ponencia el texto "La muerte: posibilidad decisiva y decisoria de la vida". Su lectura de Heidegger fue calificada por John L. Groves como neoescolástica. En Lima se editaron también dos traducciones debidas a J. Russo Delgado y a Víctor Li Carrillo. Este último fue alumno de los cursos dados por Heidegger en Alemania, lo cual explica que su versión de ¿Qué es esto, la filosofía? (U. Mayor de San Marcos, Lima, 1958) fuese publicada con una carta que su maestro le dirigió. Por otra parte, David Sobrevilla, un profesor de la misma Universidad de San Marcos, publicó un estudio sobre las ideas heideggerianas con respecto a la obra de arte. 
Bolivia: casi descansa por completo en Rubén Carrasco de la Vega, profesor de la Universidad Mayor de San Andrés, quien ha producido al menos dos cortos estudios sobre el pensamiento heideggeriano, y en Guillermo Francovich, de la Universidad de San Francisco Javier.

Costa Rica: el inmigrante vasco Teodoro Olarte, profesor universitario en San José desde 1940. La revista de esta Universidad difundió el discurso rectoral pronunciado por el filósofo alemán en 1933 y la entrevista que concedió a Richard Wisser con motivo de sus 80 años. En 1976, por su fallecimiento, la Revista de Filosofía de dicha Universidad editó tres estudios de los filósofos locales que habían promovido su recepción en Costa Rica. Desde entonces, por lo menos otros tres estudios han sido publicados en dicha revista por Annie Hayling y Roberto Castillo Rojas.

El Salvador: se registra la recepción ontológica de M. L. Escamilla, quien publicó en la Editorial Universitaria su estudio sobre La metafísica de El ser y el tiempo de Heidegger (1961), y el trabajo comparativo de Francisco Peccorini Letona.

Cuba: El filósofo Humberto Piñera Lera, quien fue presidente de la Sociedad Cubana de Filosofía, es la figura solitaria que representó el frustrado esfuerzo cubano de la recepción del pensamiento de Heidegger. Además de sus propias traducciones, publicó varios estudios de dicho pensamiento desde una perspectiva existencialista.

República Dominicana: emergió como campeón de la resistencia a la recepción del pensamiento heideggeriano el filósofo Andrés Avelino García Solano, un profesor de la Universidad de Santo Domingo, cuyas críticas a "los problemas antinómicos del existencialismo heideggeriano" fueron presentadas como una invalidación de los supuestos filosóficos de Sein und Zeit.

Colombia: Pese a que Cayetano Betancur (1910-1983) siguió la producción de los pensadores alemanes como Max Scheler, el Conde de Keyserling, Hegel y Nietzsche, así como la de los filósofos españoles (Ortega y Gasset, Unamuno y del propio Gaos), y a que su Sociología de la autenticidad y la simulación parecía indicar una apropiación de las 
ideas heideggerianas sobre la autenticidad del Dasein, la verdad es que a este filósofo, fundador de la revista Ideas y Valores de la Universidad Nacional de Colombia, la novedad de la traducción castellana de Sein und Zeit sólo parece haberle interesado como marco conceptual para la elaboración de un pensamiento católico: "Esta filosofía revela, para muchos espíritus hondamente cristianos, las posibilidades de una nueva y fecunda vinculación de la razón a la fe, respetando en todo caso la autonomía de esta última". Este uso instrumental de Sein und Zeit en Colombia también fue ejemplificado por Rafael Carrillo, quien usó el método de la analítica existencial para sus estudios sobre la naturaleza del Derecho, y por Daniel Ceballos Nieto, quien utilizó los recursos del método filológico para su interpretación del pensamiento de San Agustín. La recepción ontológica del pensamiento heideggeriano sólo pudo iniciarse en inautenticidad en la recepción latinoamericana. Por la misma época acompañó su labor divulgadora el profesor español Francisco Soler Grimma, quien por un tiempo trabajó en la Universidad Nacional de Colombia, publicando en las revistas Mito y Nuevo Extremo dos traducciones de textos heideggerianos. Una especial glosa a la Carta sobre el humanismo fue publicada en la revista Mito por Carlos Rincón. La revista bogotana Eco, que se trazó como uno de sus dos objetivos "la transmisión de bienes culturales de procedencia europea" (editorial de Ernesto Volkening, 1971), fue por ello el órgano de divulgación del pensamiento y de la literatura alemanas más eficaz de cuantos han existido en Colombia. Allí fueron divulgadas las traducciones de textos heideggerianos debidas al ya citado Soler Grimma, así como a Antonio de Zubiaurre, Jorge Rodríguez, Ramón Pérez Mantilla, Tulia de Dross, Freddy Téllez y otros. Guillermo Hoyos Vásquez ha contribuido también a las versiones colombianas de textos heideggerianos, y la entrevista concedida por Heidegger a la revista L'Express (No. 954, 20-26 oct. de1969) fue vertida al castellano por Julio Díaz Báez. La primera reseña colombiana de Sein und Zeit apareció en la revista Ideas y valores en 1951, fruto de F. Carmona Menclares, un profesor de la Facultad de Filosofía de la Universidad de México. El evento académico más significativo para el balance de la recepción del pensamiento heideggeriano en Colombia fue el primer coloquio organizado en Bogotá, a finales de noviembre de 1979, por la Sociedad 
Colombiana de Filosofía bajo el título de "Heidegger y la historia de la filosofía". Las cuatro ponencias expuestas en este coloquio por los filósofos José Lorite Mena, Guillermo Hoyos Vásquez, Daniel Herrera y Carlos B. Gutiérrez fueron la presentación pública en Colombia de la filosofía de Heidegger. Agregamos a ellas los estudios realizados por Magdalena Holguín y Jaime Hoyos Vásquez, S.J. A este evento siguió el Coloquio Alemán-Latinoamericano sobre Heidegger, cuya segunda reunión fue realizada en Bogotá entre el 29 y el 31 de marzo de 1993. Allí presentaron sus ponencias los filósofos Carlos B. Gutiérrez ("La interpretación heideggeriana del actuar humano") y Ramón Pérez Mantilla ("Heidegger y Nietzsche"). La divulgación de las obras de Heidegger se ha limitado a las cátedras universitarias de las carreras de Filosofía. Desde allí han promovido la recepción, además de los ya mencionados, los filósofos Jaime Vélez Sáenz, Rosa Helena Santos, Darío Botero Uribe y Danilo Cruz Vélez. Este último es quien por tiempo más prolongado ha examinado en Colombia todos los aspectos de Sein und Zeit y las vicisitudes de la vida personal del filósofo, al punto que, según Rubén Sierra Mejía, "acusa una mayor y más sana influencia heideggeriana: es de la filosofía de Heidegger de donde proceden los conceptos con que construye su discurso". La recepción en Medellín dependió de la labor difusora de la revista de la traducción del texto "Introducción a la metafísica" realizada por José María Valverde y publicada originalmente en los Cuadernos hispanoamericanos de Madrid (No. 56, 1954). Allí mismo se acogió también la oposición a las ideas de Heidegger, entendido como pensador "existencialista", presentada por Julio Enrique Blanco. Recientemente, el profesor Jorge Mario Mejía ha divulgado en la Revista de la Universidad de Antioquia su traducción del texto "La pregunta por la técnica" (No. 205, jul.-sep. 1986, p. 4868), cuya calidad puede ser comparada con la realizada en España por Eustaquio Barjau. Adicionalmente, el profesor de la Universidad Pontificia Bolivariana, Gildardo Lotero Orozco, publicó un ensayo sobre el discurso pronunciado por Heidegger al tomar posesión de la rectoría de la Universidad de Friburgo. La revista de la Facultad de Arquitectura de la Universidad Nacional (sede de Medellín), titulada Morar, publicó en su primera entrega (junio de 1995) una traducción de la conferencia "Construir, morar y pensar". La recepción en Cali 
corrió a cargo de William Betancourt, quien además de traducir el curso del semestre de verano de 1927 (Los problemas fundamentales de la fenomenología) produjo su propia versión de "El concepto de "filosofía" en Martín Heidegger", ambos textos publicados en Praxis Filosófica (10/11, diciembre de 1999), revista de la Universidad del Valle. En 2007 la Pontificia Universidad Javeriana publicó los aportes de autores nacionales e internacionales al Encuentro Internacional 'Heidegger: el testimonio del pensar', compilados por Luis F. Cardona.

Un tema especial como es el de las relaciones afectivas de Heidegger con la filósofa judía Hannah Arendt (1906-1975), discípula suya en la Universidad de Marburgo, tuvo un interés reciente. El artículo conmemorativo del octogésimo cumpleaños del filósofo, que Arendt publicó en 1969 en la revista alemana Merkur, fue vertido al castellano por Julio Bayón y publicado inmediatamente en el número 84 (segunda época, marzo de 1970) de la Revista de Occidente (reeditado en el número 187 de la misma revista, en diciembre de 1996). Una historia de esas relaciones fue realizada por Elzbieta Ettinger, profesora de Humanidades en el Massachusetts Institute of Technology, quien tuvo el privilegio de leer la correspondencia íntima de la filósofa. Un comentario sobre esa relación también fue publicada por Luis Fernando Moreno Claros en la Revista de Occidente. Pese a estos esfuerzos comprensivos de esa relación personal, la recepción hispanoamericana apenas ha fluctuado entre los dos polos opuestos: ignorarla o reducirla a un chisme.

\section{Ediciones, traducciones y recepción:}

Por disposición de Heidegger, la editorial alemana V. Klostermann ha venido publicando sus Obras completas sin modificaciones en lengua alemana, bajo la dirección del editor Friedrich Wilhelm von Hermann. De los sesenta volúmenes previstos ha aparecido ya más de la mitad de ellos. La proporción de la obra completa traducida al castellano, como se acaba de registrar, es baja pero significativa. En la actualidad el esfuerzo de traducción y de recepción se concentra en España, donde recientemente se han dado a conocer los textos de algunos cursos ofrecidos por Heidegger, versiones mejoradas de 
textos anteriormente traducidos por latinoamericanos y textos que habían permanecido hasta ahora sin traducir. A ello se agregan las traducciones castellanas de las obras del filósofo italiano Gianni Vattimo, cuya Introducción a Heidegger (Barcelona, Gedisa, 2a . ed., 1993) pretende ayudar al lector en su lectura de los libros más conocidos del filósofo alemán. ¿Significa esto que Hispanoamérica estará ausente de la filosofía futura, la cual, en la autorizada opinión de Gutiérrez Girardot, "se medirá y se perfilará en y con Heidegger"? ¿Serán las nuevas modas un obstáculo para que los filósofos latinoamericanos puedan perseverar en su interés y devoción hacia el último gran filósofo del siglo XX? ¿Repensarán, en y con Heidegger, la filosofía del futuro? Un examen de las ponencias presentadas por buena parte de los filósofos latinoamericanos al XIII Congreso Interamericano de Filosofía, realizado en Bogotá del 4 al 9 de julio de 1994, no ofrece muchas esperanzas en tal dirección. Allí sólo pudo verse la continuidad de la recepción heideggeriana en Alberto Rosales (Universidad Simón Bolívar de Caracas) y Ramón Pérez Mantilla (Universidad Nacional de Colombia), acompañados por los nuevos esfuerzos de Carlos Másmela (Instituto de Filosofía de la Universidad de Antioquia) y Javier Domínguez (Universidad de Antioquia). La única novedad fue la presentación de la tarea de recepción realizada en Brasil por Zeljko Loparic, un profesor de la Universidad de Campinas. En resumen, sólo cinco voces solitarias en el conjunto de los ponentes del mencionado congreso, a las que podemos agregar la del filósofo italiano Gianni Vattimo. Muy poco para todo el conjunto de filósofos latinoamericanos de nuestros días, tan interesados en el debate sobre modernidad y postmodernidad. No obstante, en Argentina se mantiene el interés gracias al sitio creado y actualizado en el ciberespacio por Horacio Potel, el cual permite a los interesados el acceso gratuito a una parte significativa de las traducciones españolas disponibles de los textos del filósofo. En su crítica revisión de los trabajos filosóficos producidos en Colombia durante la última década del siglo XX, Carlos Sánchez consideró que los profesores que enseñan filosofía son "uno de los obstáculos más serios para el avance de la filosofía en Colombia". Bajo el amparo de "currículos de filosofía improvisados", del abandono del estudio de las lenguas clásicas y del alemán, estos profesores parecen 
haber estimulado en la nueva generación una lectura del pensamiento alemán como si fuesen "novelas de libre interpretación polisémica", antes que situarla en un riguroso contexto hermenéutico o filológico. Esa entronización de los "balcones burocráticos" en las universidades parecería haber cerrado toda esperanza de una recepción crítica de la obra heideggeriana, pese a la disponibilidad de mejores traducciones castellanas. No obstante, el magisterio ejercido en Colombia por Danilo Cruz Vélez, Rubén Jaramillo Vélez, Carlos Másmela y Carlos B. Gutiérrez es una indicación de que no está asegurado el triunfo del "burócrata anónimo de caminar lento, palabra pausada y discurso insustancial". Serán la disciplina y el rigor de la nueva generación las que dirán la última palabra.

\section{Mi propia experiencia:}

Esta se vincula: 1) con mi gran interés por el pensamiento heideggeriano, por las razones que expresé al comienzo al referirme a su importancia e influencia, que me llevaron a conocerlo en detalle, explorarlo y dialogar con él desde mi propio contexto histórico cultural, 2) y con la tarea de traducción al castellano de varias de sus obras, surgida ante la necesidad de ofrecer textos del filósofo aún no traducidos, para los Seminarios que dedicaba a diferentes aspectos de su pensamiento. La traducción me significó un renovado y profundo contacto con los mismos, porque en esa esforzada tarea de llevar al castellano el meditado y singular lenguaje alemán del autor, me vi precisada a adentrarme más en su siempre pensante y creativa búsqueda y exposición de un sentido originario a través de la sabiduría del lenguaje, pasadera estrecha pero valiosa e imprescindible. Debo decir que continúo siendo fuertemente atraída por esas sendas que el autor abre en confrontación con la tradición, con los hechos y a través del lenguaje, en pos de un sentido y desde la dimensión originaria del ser como acaecer, lo cual permite pensar desde lo abierto de la historia y los caminos que ella ofrece y también sustrae. Para mí significaba además la posibilidad de pensar la propia experiencia de nuestro contexto histórico latinoamericano, por lo que se trata siempre de un diálogo con esta obra, desde el propio lugar, en el que 
se aprende a andar los caminos de la tradición occidental hasta el mismo Heidegger, en la síntesis histórica siempre renovada de pasado como espacio de experiencia, presente como actualización y futuro como horizonte de posibilidades; un pensar que recoge lo acaecido y promete respuestas, devolviendo ser y sentido a las cosas y a los hombres en el habitar de un mundo, en una época que objetiva y mercantiliza a las cosas y los hombres. 